[Title Page]

\title{
Novel Methods for Estimating Lithium-Ion Battery State of Energy and Maximum Available Energy
}

Linfeng Zheng, ${ }^{\mathrm{a}, \mathrm{b}}{ }^{*}$, Jianguo Zhu ${ }^{\mathrm{a}}$, Guoxiu Wang ${ }^{\mathrm{b}}$, Tingting $\mathrm{He}^{\mathrm{a}}$, Yiying Weia,

a. Faculty of Engineering and Information Technology, University of Technology Sydney, Sydney, N.S.W., 2007, Australia

b. Centre for Clean Energy Technology, University of Technology Sydney, Sydney, N.S.W., 2007, Australia

*Corresponding author:

Linfeng Zheng, Faculty of Engineering and Information Technology, University of Technology Sydney, Sydney, N.S.W., 2007, Australia. Email: Linfeng.Zheng@student.uts.edu.au. 


\section{Abstract}

$4 \quad$ The battery state of energy (SOE) allows a direct determination of the ratio between the

5 remaining and maximum available energy of a battery, which is critical for energy

6 optimization and management in energy storage systems. In this paper, the ambient

7 temperature, battery discharge/charge current rate and cell aging level dependencies of

8 battery maximum available energy and SOE are comprehensively analyzed. An explicit

9 quantitative relationship between $\mathrm{SOE}$ and state of charge (SOC) for $\mathrm{LiMn}_{2} \mathrm{O}_{4}$ battery

10 cells is proposed for SOE estimation, and a moving-window energy-integral technique

11 is incorporated to estimate battery maximum available energy. Experimental results

12 show that the proposed approaches can estimate battery maximum available energy and

13 SOE with high precision. The robustness of the proposed approaches against various

14 operation conditions and cell aging levels is systematically evaluated.

16 Key words: Battery management system (BMS); State of energy (SOE); State of 17 charge (SOC); Maximum available energy. 


\section{Introduction}

Lithium-ion batteries have many desirable merits such as high energy density, light weight and long cycle life, and are widely developed as energy storage devices in smart grids and electric vehicles $[1,2]$, etc. To meet the application power and energy demands, a battery system usually contains hundreds, even thousands of cells connected in series and parallel. To ensure safe and reliable operation, an effective battery management system (BMS) is required to monitor and control these cells. Much of the BMS functionalities, such as the state of charge (SOC) estimation, state of health estimation, cell monitoring and balancing techniques [3-8], have been sophisticatedly developed for applications. Nevertheless, due to the nonlinear battery characteristics and unpredictable operating conditions, accurate and reliable battery state of energy (SOE) and maximum available energy estimations still pose significant challenges.

Traditionally, the SOC is regarded as an indicator of battery available energy. A wide variety of approaches for SOC estimation has been reported in recent literature [2,9-19], and remarkable results have been achieved on novel SOC estimation methods and improving the estimated accuracy. For example, the proportional-integral (PI) observer [11], Luenberger observer [12,13], Sliding-mode observer [14,15] and Kalman-filterbased algorithms [2,16-19] were employed in model-based SOC estimation methods to obtain estimated results of high accuracy. Defined as the ratio of the remaining charge stored in a battery to its full capacity, however, SOC actually indicates the state of available capacity rather than the state of available energy. K. Mamadou etc. [20,21] 
introduced a new criterion, state of energy (SOE), for battery energetic performances evaluation. SOE allows a direct determination of the ratio of battery remaining energy to its maximum available energy, which is critical for energy optimization and management in energy storage systems.

Compared with the SOC estimation approaches, there are few studies report the systematic research for SOE estimation. Refs. [22,23] presented SOE estimation methods based on Neural Network, which treats the target battery as a "black-box" system and needs a great number of sample data to train the network parameters. The main disadvantage of this method is that the estimation errors are strongly dependent on the training data. In [24,25], an adaptive unscented Kalman filter algorithm and the relationship between the SOE and open circuit voltage (OCV) were employed in the model-based SOE estimation approaches. In [26], the particle filter and a battery model are utilized to develop a method for joint estimation of the SOE and the SOC, and the robustness of the method has been verified under dynamic temperature conditions. $\mathrm{H}$. He etc. [27] employed a Gaussian model oriented battery model and proposed a datadriven estimator with a central difference Kalman filter algorithm for SOE estimation, and the approach was evaluated by two kinds of batteries including $\mathrm{LiFePO}_{4}$ and $\mathrm{LiMn}_{2} \mathrm{O}_{4}$ cells. Although these SOE estimation approaches are able to achieve acceptable accuracy, the complex algorithms produce a heavy computational burden on the microprocessor with limited computation capability within BMSs.

Besides, a common drawback of these SOE estimation methods is that they fail to 
achieve desirable predictions against various operating conditions during battery aging processes. The trajectory of the neural network parameters or battery model parameters cannot be fully described within a limited number of experiments [27]. Various battery operating conditions and cell aging levels with pre-set parameters may lead to inaccurate SOE estimated results. It is also noted that the above-mentioned battery available energy studies focus just on the SOE estimation. Unfortunately, there are very few studies involving the estimation of battery maximum available energy (i.e. battery actual energy). Since the battery maximum available energy is strongly related to the battery operating conditions [22], it is necessary to systematically study the effects of ambient temperature, current rate, and aging level in order to estimate the SOE and maximum available energy more accurately, and further improve the robustness of estimation approaches against uncertain operating conditions.

To implement this work, a battery test bench was developed, and the characteristics of $\mathrm{LiMn}_{2} \mathrm{O}_{4}$ battery cells with a nominal capacity of $90 \mathrm{Ah}$ were tested under different aging levels, current rates, and ambient temperatures. The tests cover a broad aging level range from $92 \mathrm{Ah}$ to $69.5 \mathrm{Ah}$, a wide temperature range from $10{ }^{\circ} \mathrm{C}$ to $40{ }^{\circ} \mathrm{C}$ and a commonly used current rate range from $1 / 3 \mathrm{C}$ to $1 \mathrm{C}$. Based on the test data, the relationships between SOE and SOC under various operating conditions are systematically analyzed and quantified for SOE estimation. A moving-window energyintegral technique is incorporated to estimate the battery maximum available energy. The robustness and feasibility of the proposed approaches are validated in different operating condition tests during battery aging processes. 
The remainder of the paper is arranged as follows: Section 2 introduces the battery test bench and analyzes the dependencies of battery available energy and SOE on the temperature, current and cell aging level. Section 3 presents the proposed algorithms of battery SOE and maximum available energy estimations. The experimental results and evaluation of the proposed approaches are reported in Section 4, followed by the conclusions and future work in Section 5.

\section{Battery Experiments and Results}

\subsection{Battery Test Bench}

The $\mathrm{LiMn}_{2} \mathrm{O}_{4}$ cells with a nominal capacity of $90 \mathrm{Ah}$ were used to investigate the battery energy characteristics at various experimental conditions of different ambient temperatures, current rates, and cell aging levels. A battery test bench was set up to obtain battery characterization experimental data, as shown in Fig. 1.

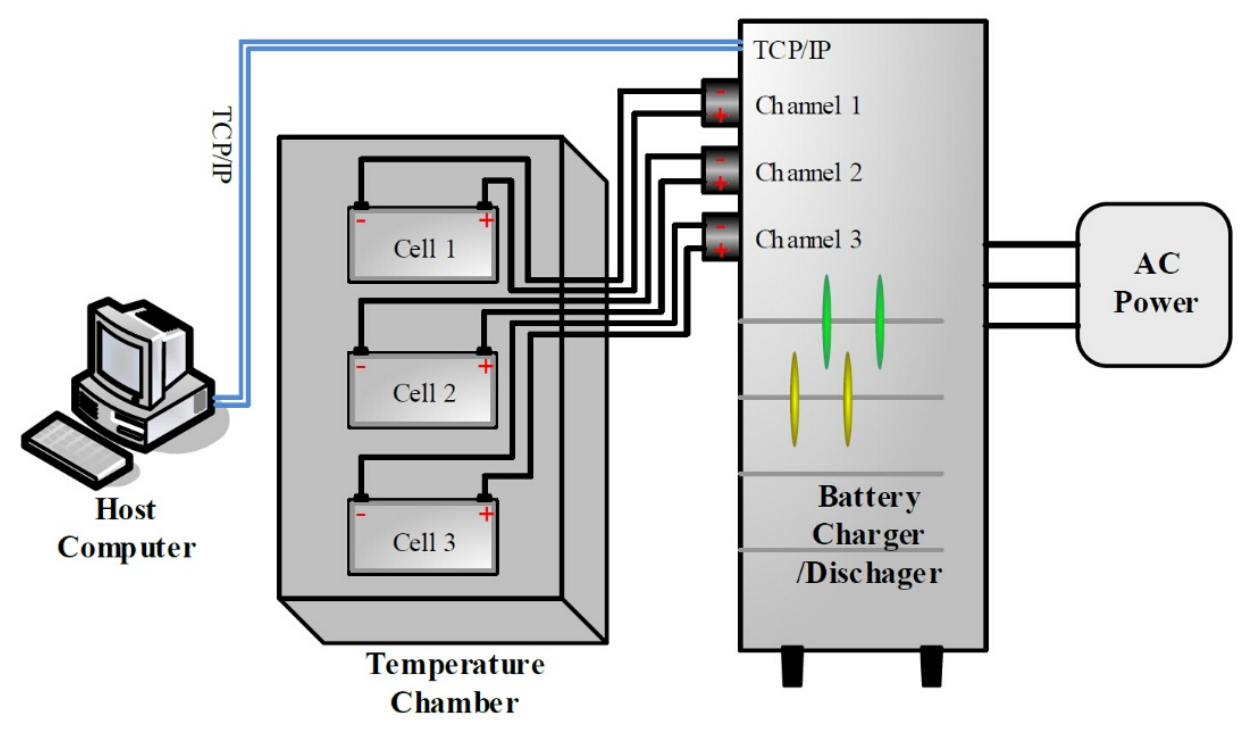

Fig. 1. Configuration of the battery test bench. 
The battery test bench is composed of a battery charger/discharger, a host computer, a programmable temperature chamber and Lithium-ion battery cells. The battery charger/discharger functions to charge or discharge battery cells according to preset loading profiles and its voltage and current measurement accuracy is $0.05 \%$ full scale. The host computer is used to set the loading profiles and control the battery charger/discharger through the TCP/IP communications. It is also used to record a set of real-time battery variables, such as battery terminal voltage, loading current, and charge/discharge energy. The programmable temperature chamber can simulate various ambient temperatures and is used to control the battery operated under the designed temperatures.

\subsection{Temperature, current and aging level dependencies of battery maximum available} energy

In order to investigate the battery maximum available energy with different currents at various ambient temperatures, the battery cells were loaded with the discharge current rates of $\mathrm{C} / 3,2 \mathrm{C} / 3, \mathrm{C} / 2$ and $1 \mathrm{C}$ at temperatures of $10^{\circ} \mathrm{C}, 25^{\circ} \mathrm{C}$ and $40{ }^{\circ} \mathrm{C}$, respectively. At each temperature, the battery cells were firstly charged with a preset constant current to the upper limit voltage $4.2 \mathrm{~V}$ followed by a constant voltage charge at $4.2 \mathrm{~V}$ until $\mathrm{C} / 20$ cutoff. Then, there was a rest time for $1 \mathrm{~h}$ followed by the preset constant current discharge to the lower limit voltage $3 \mathrm{~V}$. After that, the battery was given a rest for $1 \mathrm{~h}$ and the procedure was carried out repeatedly. During the battery discharge processes, the maximum available energy results with different currents at various temperatures 


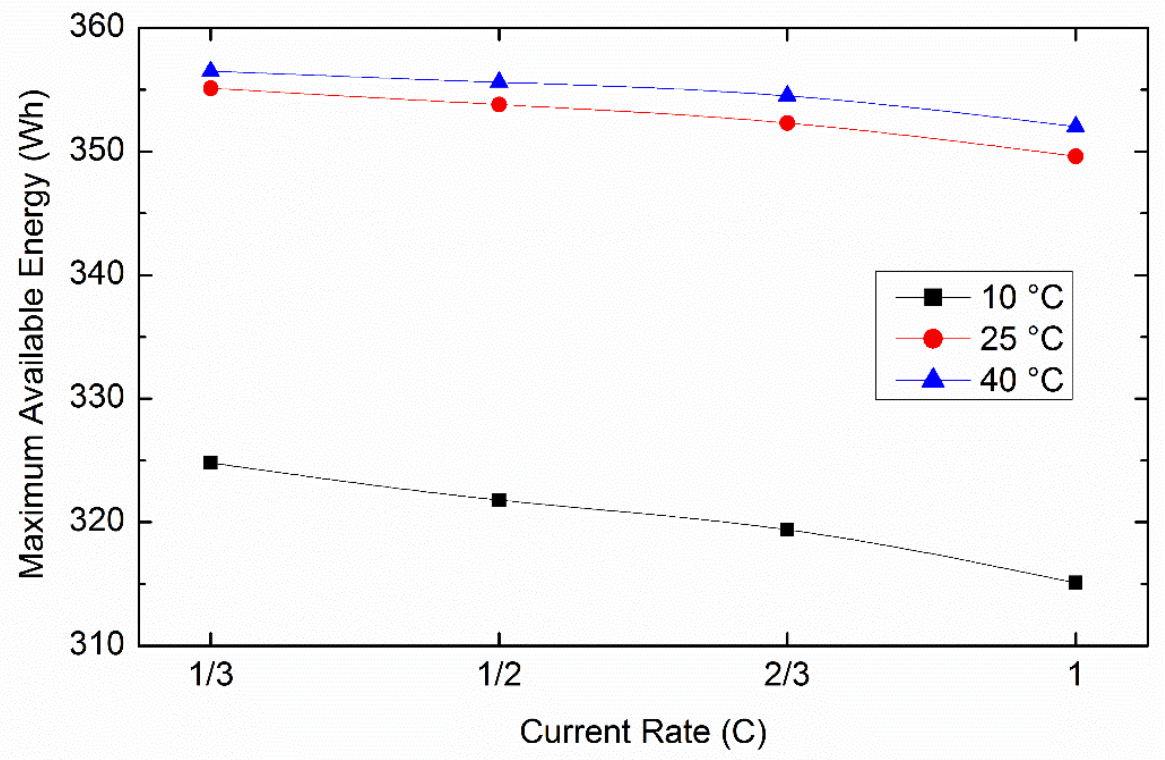

Fig. 2. The maximum available energy with different currents at various temperatures.

From Fig. 2, it can be found that the battery maximum available energy presents a

122 change with different currents at various temperatures. At the same ambient temperature,

123 the available energy appears a decreasing trend with the increasing discharge current rate. For example, when the discharge current rate was increased from $1 / 3 \mathrm{C}$ to $1 \mathrm{C}$, the available energy dropped from $324.8 \mathrm{Wh}$ to $315.1 \mathrm{Wh}$ at $10{ }^{\circ} \mathrm{C}$. At various temperatures,

126 when the discharge current rate is kept at $1 / 3 \mathrm{C}$, the maximum available energies are 324.8 Wh, 355.1 Wh, and $356.5 \mathrm{Wh}$ at $10^{\circ} \mathrm{C}, 25^{\circ} \mathrm{C}$ and $40^{\circ} \mathrm{C}$, respectively, presenting an increasing trend with the rising temperature.

129 To investigate the battery maximum available energy with different currents at various battery cell aging levels, accelerated aging tests with the charge/discharge current of 1C at $60{ }^{\circ} \mathrm{C}$ were applied to the battery cell to obtain different cell aging levels including 
92 Ah, 87 Ah, 82.5 Ah, 78 Ah, 74.5 Ah and 69.5 Ah, and at each cell aging level, the battery cell was loaded with the discharge currents of $\mathrm{C} / 3, \mathrm{C} / 2,2 \mathrm{C} / 3$ and $1 \mathrm{C}$ at the room temperature $\left(25^{\circ} \mathrm{C}\right)$, respectively. The battery maximum available energy values are plotted in Fig. 3.

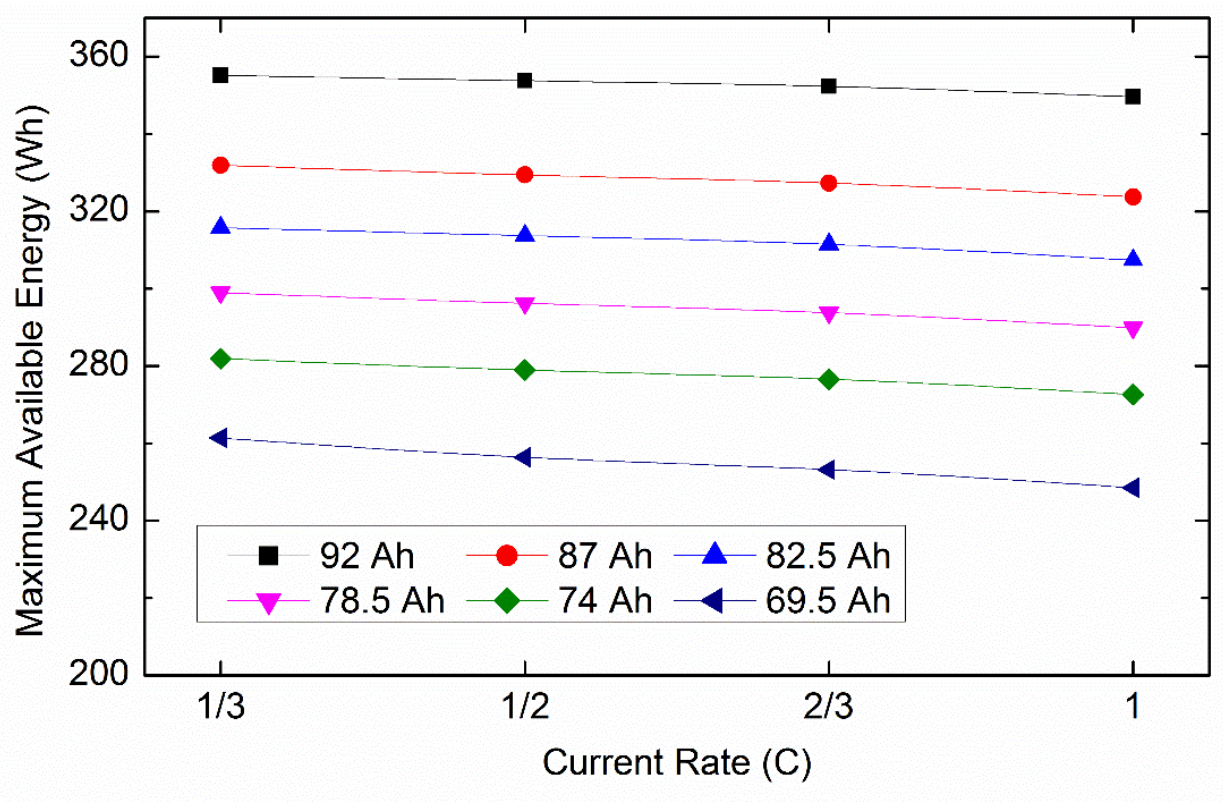

Fig. 3. The maximum available energy with different currents at various aging levels.

In Fig. 3, when the discharge current rate is $1 / 3 \mathrm{C}$, the battery maximum available energy values are 355.1 Wh, 331.9 Wh, 315.8 Wh, 299.0 Wh, 281.9 Wh and 261.4 Wh at the battery capacity $92 \mathrm{Ah}, 87 \mathrm{Ah}, 82.5 \mathrm{Ah}, 78.5 \mathrm{Ah}, 74 \mathrm{Ah}$ and $69.5 \mathrm{Ah}$, respectively. The maximum available energy shows similar declining trends with different discharge current rates such as $1 / 2 \mathrm{C}, 2 / 3 \mathrm{C}$, and $1 \mathrm{C}$ at different aging levels, indicating that the battery maximum available energy appears a significant decrease during battery aging processes.

It can be concluded that the battery maximum available energy varies with the operating 
conditions and is greatly related to the ambient temperature and cell aging level. Accordingly, it is necessary to develop reliable approaches for accurate battery maximum available energy and SOE estimations with strong robustness against the varying operating conditions during the battery aging processes.

\subsection{Temperature, current and aging level dependencies of the relationship between} SOE and SOC

Being similar to the SOC range, the SOE reaches its maximum value $100 \%$ when the battery is fully charged which means it has the maximum available energy, and it reaches its minimum value $0 \%$ when the battery is fully discharged which means there is not any remaining energy can be discharged. Since the battery charger/discharger is able to measure cell voltage and loading current with high precision, the referenced data are represented by the measurement data detected by the charger/discharger which are recorded in the host computer. The recorded data include the battery cell terminal voltage, loading current, charge/discharge capacity and energy, and therefore the SOC and SOE can be easily calculated by Eq. (1) and Eq. (2), respectively,

$\operatorname{SOC}(k)=\operatorname{SOC}(k-1)+\eta_{C} I(k) \Delta t / C_{a}$

$\operatorname{SOE}(k)=\operatorname{SOE}(k-1)+U(k) I(k) \Delta t / E_{a}$

where $S O C(k)$ denotes the SOC value at time $k, S O C(k-1)$ the SOC value at time $(k-1)$, $\operatorname{SOE}(k)$ the SOE value at time $k, \operatorname{SOE}(k-1)$ the SOE value at time $(k-1), \Delta t$ the sampling time interval, $I(k)$ the loading current at time $k$ (positive for charging and negative for 
discharging), $U(k)$ the battery cell terminal voltage at time $k, C_{a}$ the battery maximum available capacity (i.e. the battery actual capacity), $E_{a}$ the battery maximum available energy (i.e. the battery actual energy), and $\eta_{C}$ the coulombic efficiency which is considered to be approximately equal to 1 [26].

It has been reported that there is a positive correlation between the SOE and SOC [24], but the relationship between SOE and SOC has not been clearly defined. Thus, the relationship between SOE and SOC should be further studied. To investigate the temperature dependency of the relationship between SOE and SOC, different battery cells of the same batch were loaded with the discharge current $\mathrm{C} / 3$ at $10{ }^{\circ} \mathrm{C}, 25^{\circ} \mathrm{C}$ and $40{ }^{\circ} \mathrm{C}$, respectively. The relationships between $\mathrm{SOE}$ and SOC at different temperatures are plotted in Fig. 4 where the SOC is regarded as the $\mathrm{X}$-axis and the SOE as the Y-axis.

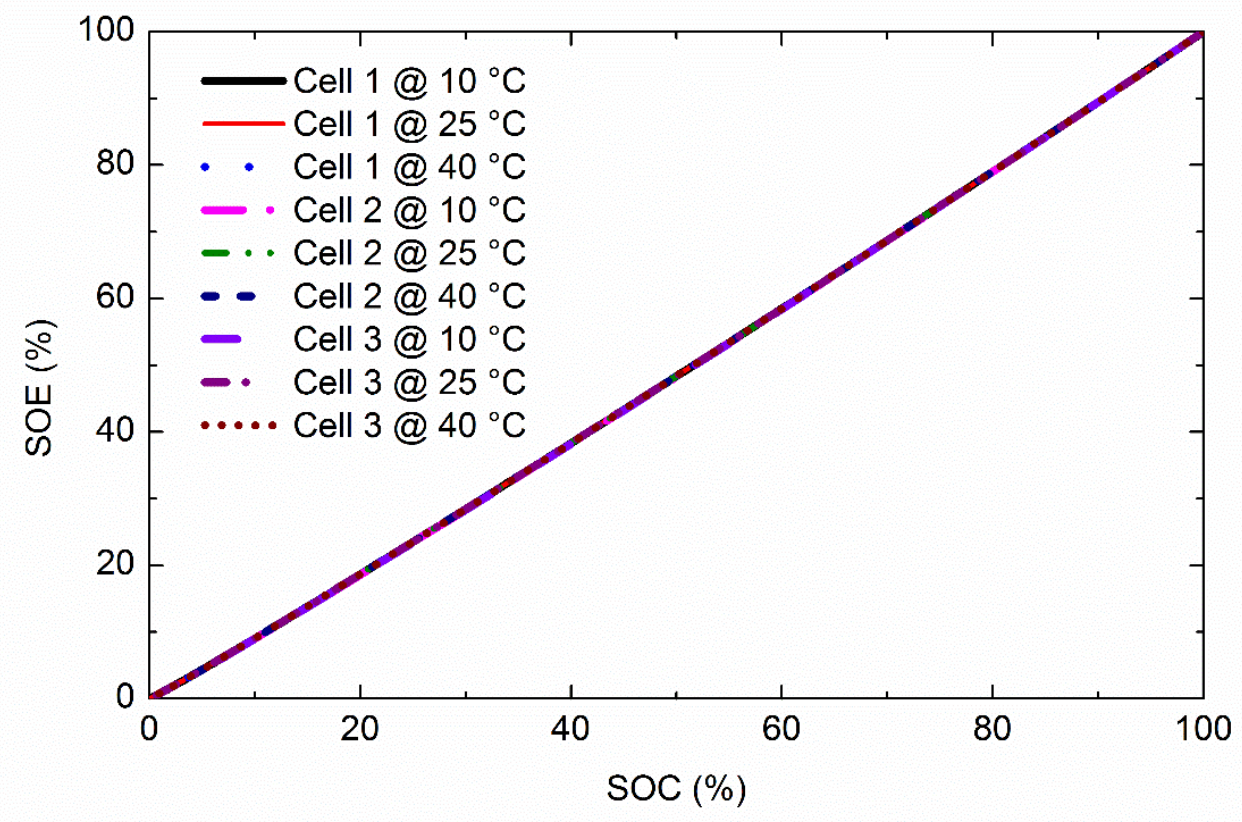

Fig. 4. The relationships between SOE and SOC at different temperatures.

Fig. 4 shows a perfect coincidence among the relationships between SOE and SOC at 
different temperatures. It indicates that the relationship between SOE and SOC has strong robustness against the changing ambient temperature. Besides, it is noted that for three different cells of the same batch, the relationships between SOE and SOC also coincide well with each other. Thus, the relationship between SOE and SOC can be readily extended for each cell of whole battery pack operated at different ambient temperatures.

In order to investigate the current dependence of the relationship between SOE and SOC, the battery cells were loaded with the discharge and charge current rates of $\mathrm{C} / 3$, $\mathrm{C} / 2,2 \mathrm{C} / 3$ and $1 \mathrm{C}$, respectively. The results are shown in Fig. 5.

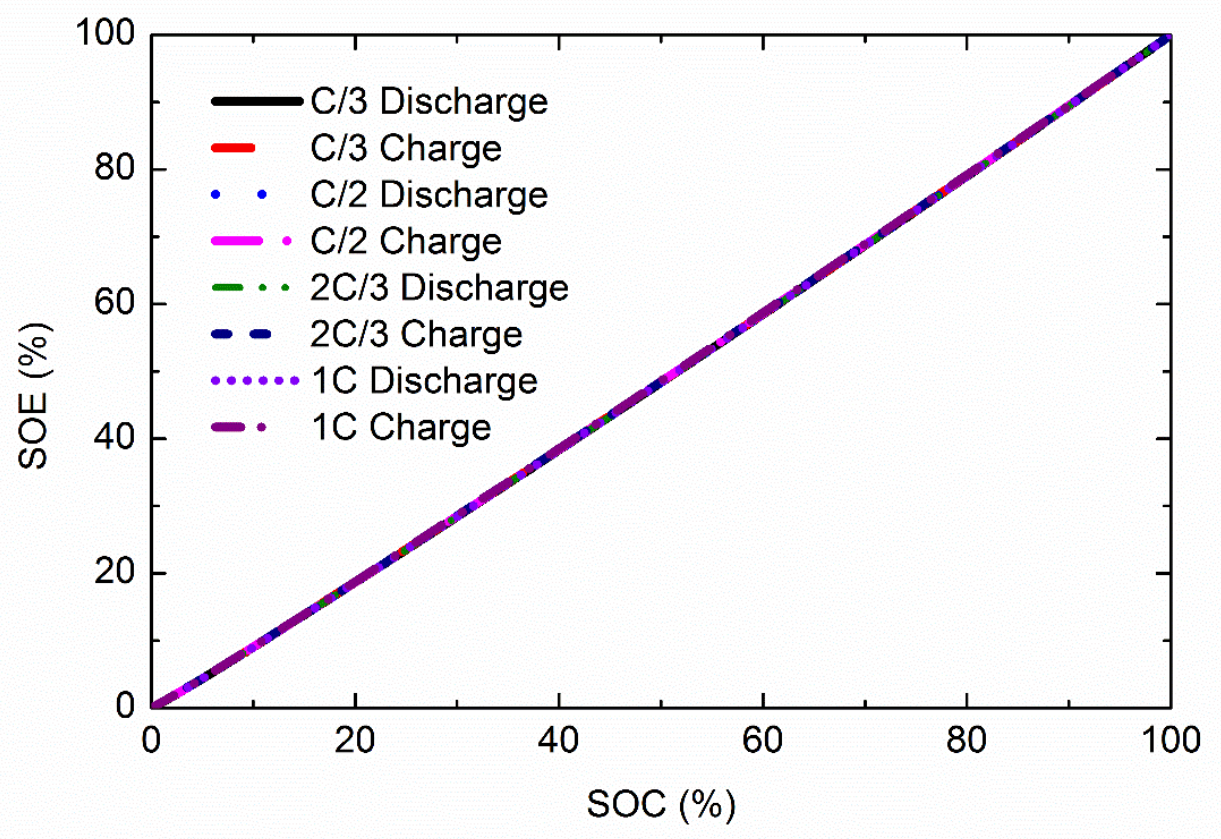

Fig. 5. The relationships between SOE and SOC with various current rates.

From Fig. 5, it can be seen that the relationships between SOE and SOC with various discharge or charge current rates almost coincide with each other. It manifests that the charging and discharging current rates have little effect on the relationship between 
194

195

196

197 198 199 200 201 202

SOE and SOC. Thus, the relationship can be applied not only in battery constant current charging/discharging processes but also in dynamic changed current working conditions.

To investigate the aging level dependence of the relationship between SOE and SOC, the battery cell was loaded with a discharging current rate of $\mathrm{C} / 3$ at battery capacity degraded from $92 \mathrm{Ah}$ to $69.5 \mathrm{Ah}$, respectively, and the relationships are shown in Fig. 6.

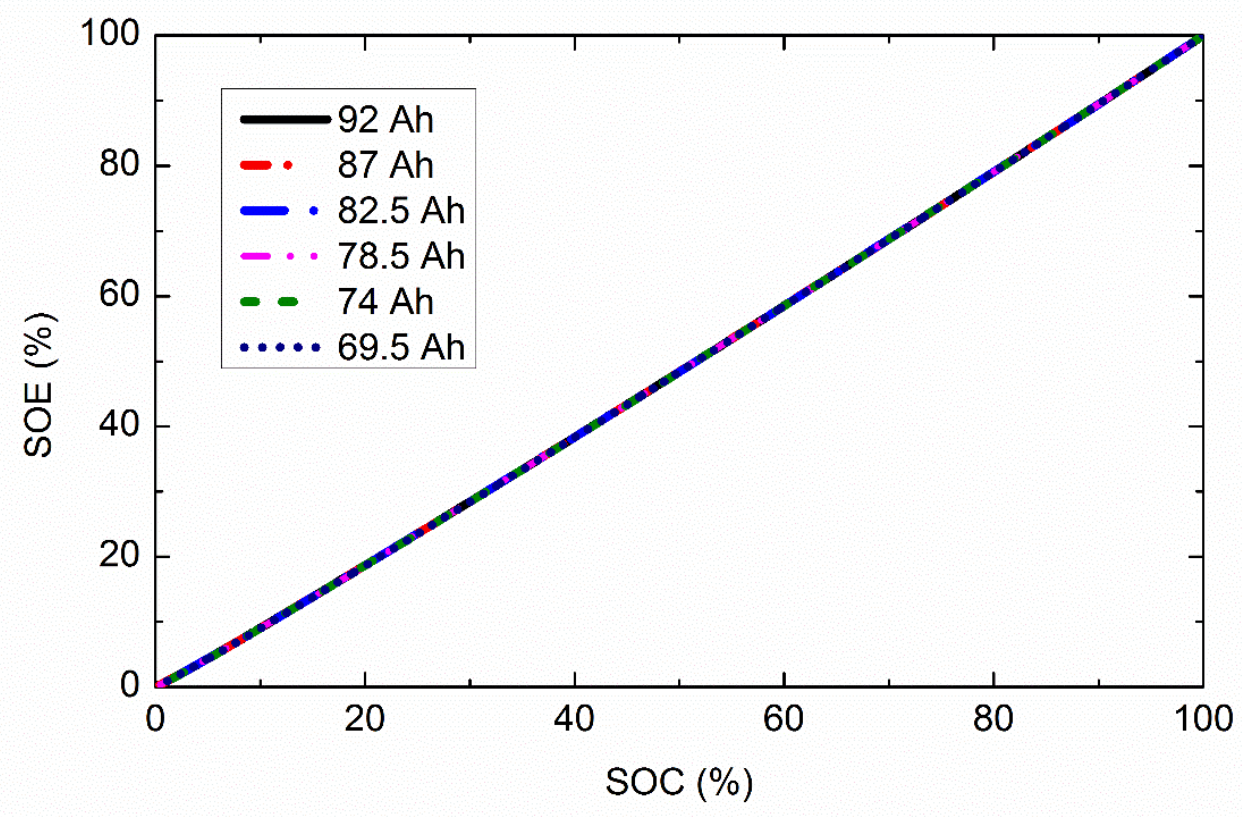

Fig. 6. The relationships between SOE and SOC at different aging levels.

In Fig.6, the relationships between SOE and SOC at different aging levels appear a superior overlapping characteristic. It demonstrates that the relationship between SOE and SOC remains steady during battery aging processes and has strong robustness against the battery capacity fade. 
From above experimental results, it can be summarized that under different operating conditions and cell aging levels, the relationship between battery SOE and SOC always keeps unchanged. Although the maximum available energy and maximum available capacity of a battery cell are significantly dependent on its operated ambient temperature, loading current rate and aging level, it is noted that these factors have negligible effects on the relationship between SOE and SOC. This is because the SOE and SOC values were calculated by Eq. (1) and Eq. (2) with the maximum available energy and maximum available capacity, respectively, which have already included these influence factors.

\section{The Proposed Algorithms}

It has been reported that the model-based SOC estimation methods are able to achieve high estimated accuracy [9-19]. Thus, the estimated SOC and the stable relationship between SOE and SOC can be utilized to estimate SOE. According to the results shown in Figs. 4-6, the relationship between SOE and SOC can be expressed as an explicitly quantitative expression which is assumed to be a quadratic function, as given by,

$$
\operatorname{SOE}(k)=a \operatorname{SOC}(k)^{2}+b \operatorname{SOC}(k)+c
$$

where $a, b$ and $c$ are three coefficients of the quadratic function.

The coefficients of the quadratic equation are fit by using Levenberg-Marquardt algorithm [28,29] for the relationship between SOE and SOC under different temperatures, current rates, and cell aging levels. The optimal parameters are listed in 
227 Table 1 . The coefficient of determination $R$-Square is 0.999989 , which means the fitting 228 function can precisely match the real relationship between SOE and SOC.

230 Table 1. Optimal parameters of the relationship function between SOE and SOC.

\begin{tabular}{cc}
\hline Parameter & Coefficient \\
$a$ & 0.000600 \\
$b$ & 0.944954 \\
$c$ & -0.426930 \\
\hline
\end{tabular}

232 Based on the quantitative relationship between SOE and SOC with estimation SOC, the

233 overall structure of the proposed algorithms for both battery SOE and maximum 234 available energy estimation is shown in Fig. 7. 


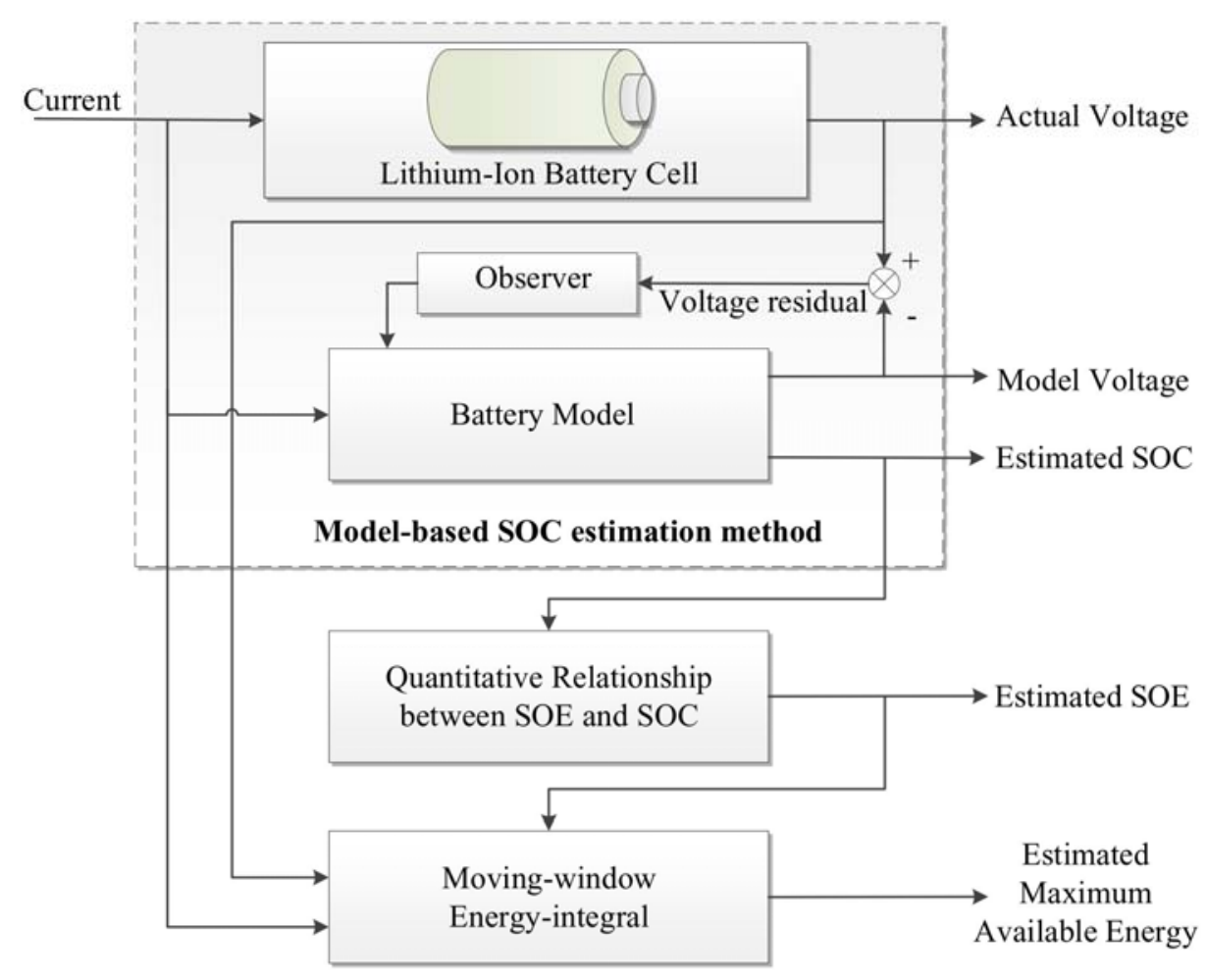

Fig. 7. The structure of the proposed algorithms.

238 The SOC is firstly estimated by a model-based estimation method. Since the model-

239 based SOC estimation method is not the emphasis of this paper, we briefly explain the

240 working principle of the method, and refer readers to Refs. [11-19,30] where give a

241 more comprehensive description on the model-based SOC estimation methods. Briefly,

242 a battery model such as equivalent circuit models and electrochemical models is

243 employed to calculate the model output voltage with the given initial SOC value and

244 loading current. Then the voltage residual between the model output voltage and the

245 cell terminal voltage (i.e. cell actual voltage) is fed to an observer or filter such as PI

246 observer, Luenberger observer, Sliding-mode observer and Kalman-filter-based filters,

247 for producing a compensation value. After that, the compensation value is used to

248 modify state variables of the battery model and therefore the estimated SOC is able to 
258 where $\sum_{i=0}^{k}(U(i) I(i) \Delta t)$ is the energy integral from the beginning time to the time $k$

track with the actual SOC.

Subsequently, the estimated SOC and the quantitative relationship are employed to estimate SOE. Furthermore, a moving-window energy-integral technique with the SOE estimation is incorporated to estimate the battery maximum available energy and its detailed estimation process is described as follows.

Eq. (2) expresses the relationship between SOE and battery maximum available energy, and therefore the battery maximum available energy can be derived reversely, as given by,

$$
E_{a}=\sum_{i=0}^{k}(U(i) I(i) \Delta t) /(\operatorname{SOE}(k)-\operatorname{SOE}(0))
$$
and $\operatorname{SOE}(0)$ is the SOE value at the beginning time.

As mentioned in Section 2, the battery maximum available energy is greatly related to the ambient temperature, cell aging level and loading current rate. However, it is noted that these three variables are not included in Eq. (4). This is because that in Eq. (4), the battery maximum available energy is calculated with the estimated SOE, which is calculated by Eq. (3). Eq. (3) describes the quantitative relationship between SOC and SOE, which was obtained by fitting the experimental SOC and SOE data under various ambient temperatures, cell aging levels and loading current rates. From Figs. 4-6, it can be seen that these variables have negligible effects on the relationship between SOE 
and SOC. Thus, the variables are not included in Eq. (3) and also not included in Eq.

269 (4). Since the SOC value is considered as the input for calculating the SOE given by Eq. (3) at different operating conditions, the SOC should be the value under the corresponding operating conditions, which has considered the variables of ambient temperature, cell aging level and loading current rate, and therefore the estimated SOE and maximum available energy values are also related to these variables.

As presented in Eq. (4), the battery maximum available energy can be calculated by using two certain SOE points such as the beginning charge/discharge point and the final charge/discharge point. However, the SOE estimation errors in these two points may

277 lead to incorrect battery maximum available energy estimation results. From experience, 278 one way to decrease the uncertainty in experimental data is to make multiple 279 measurements and take the average. Accordingly, a moving-window energy-integral 280 technique with multiple calculations is incorporated for the estimation. The battery maximum available energy is calculated in each 200 seconds' moving-window. Then

282 the average of the maximum available energy values of each moving-window is considered as the final estimated result, as given by,

$284 \quad E_{a_{-} a v g}=\sum_{i=1}^{n} E_{a i} / n$

285 where $E_{a i}$ is the maximum available energy in each moving-window and $n$ the number 286 of moving-windows. 


\section{Verification and Discussion}

\subsection{SOE estimation}

289

290

291

292

293

294

295

296

297

298

299

300

As presented in our previous SOC estimation work [13], the SOC estimation error can be limited to a $+/-2 \%$ error band and the estimated SOC can track with the referenced SOC quickly even with an erroneous initial SOC value. Combining the estimated SOC and the relationship between SOE and SOC, the SOE estimation result of a battery cell with $92 \mathrm{Ah}$ and 1/3C discharging current rate is shown in Fig. 8 where the referenced SOE values are calculated by Eq. (2) with the experimental test data.

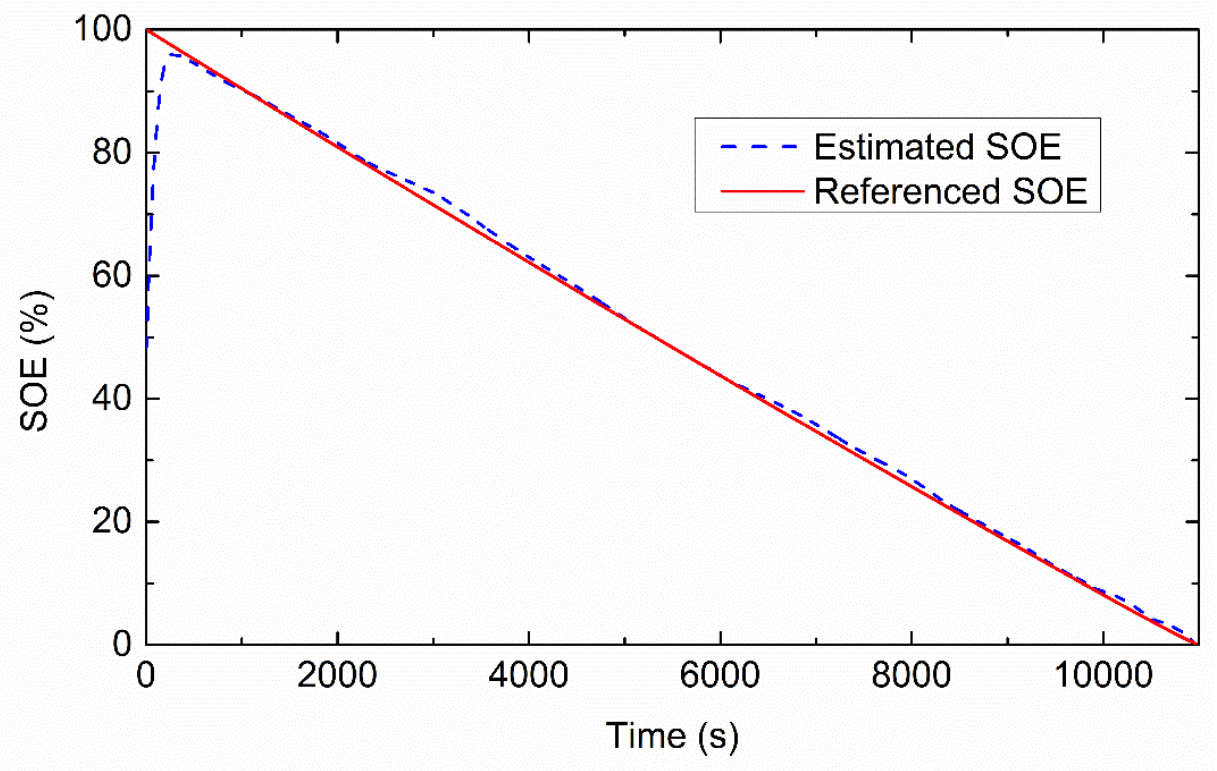

Fig. 8. SOE estimation result.

In Fig. 8, the referenced initial SOE value is $100 \%$ while there is an erroneous initial SOC value of the battery model that caused an incorrect initial SOE value $48 \%$. It can be seen that in the first $400 \mathrm{~s}$, the estimated SOE increases quickly to catch up with the referenced SOE, and therefrom the estimated SOE is able to follow the tracks of the 
referenced value well. It indicates that the proposed SOE estimation method can work well even when a grossly erroneous initial SOE value is supplied to the program. The detailed SOE estimation errors at different battery aging levels and operation conditions will be depicted as follows.

To investigate the effectiveness of the proposed method during the process of battery aging, the battery cell degraded from 92 Ah to 69.5 Ah was used for the verification. The SOE estimation errors including the maximum absolute error (MAE) and the root mean square error (RMSE) are shown in Fig. 9 at six different aging levels with $92 \mathrm{Ah}$, 87 Ah, 82.5 Ah, 78.5 Ah, 74 Ah and 69.5 Ah, respectively.

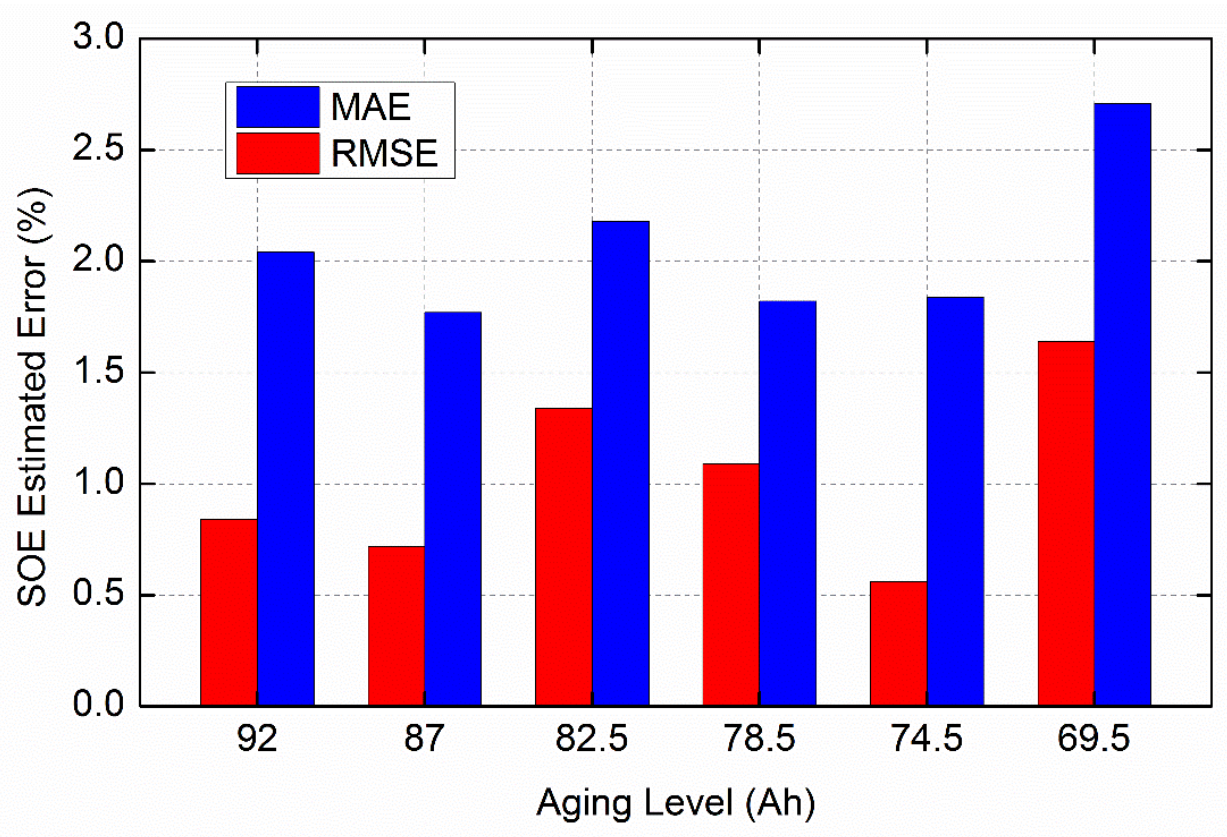

Fig. 9. SOE estimation errors at different battery aging levels.

In Fig. 9, the SOE estimation MAEs at different battery aging levels are less than $3.0 \%$ while the SOE estimation RMSEs are less than $2.0 \%$, indicating that the proposed method can handle different battery aging levels quite well. 

effectiveness of the proposed method under different ambient temperatures. The SOE estimation errors are shown in Fig. 10.

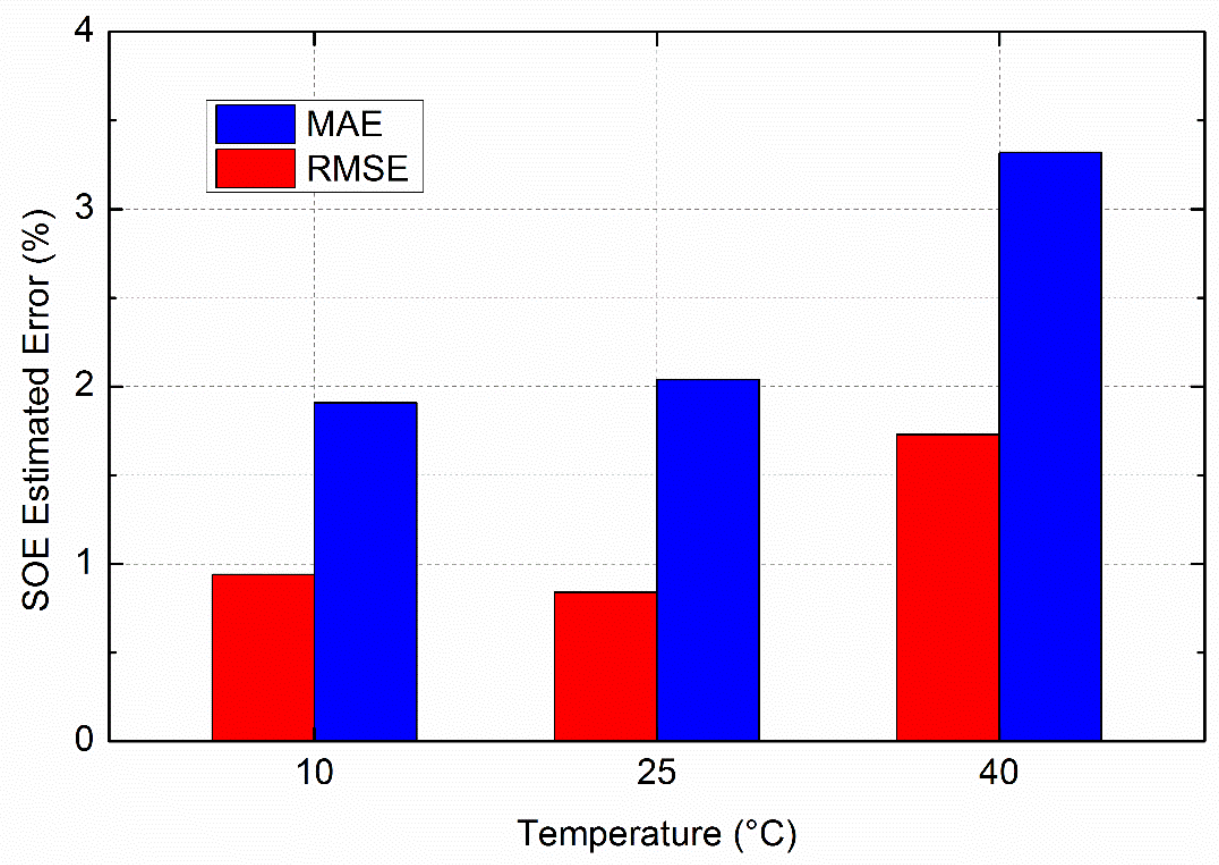

Fig. 10. SOE estimation errors under various ambient temperatures.

From Fig. 10, it can be seen that the maximum SOE estimation MAE occurred at $40{ }^{\circ} \mathrm{C}$, which is about $3.32 \%$. At different ambient temperatures, the SOE estimation RMSEs are less than $2.0 \%$. It can be concluded that the proposed approach is able to achieve desirable SOE estimation results under various ambient temperatures.

To investigate the effectiveness of the proposed method with different charge current 325 rates, the characteristic test data with four discharging current rates: $1 / 3 \mathrm{C}, 1 / 2 \mathrm{C}, 2 / 3 \mathrm{C}$ and $1 \mathrm{C}$ at the room temperature $\left(25^{\circ} \mathrm{C}\right)$ were used to verify the method. The SOE estimation errors are shown in Fig. 11. 


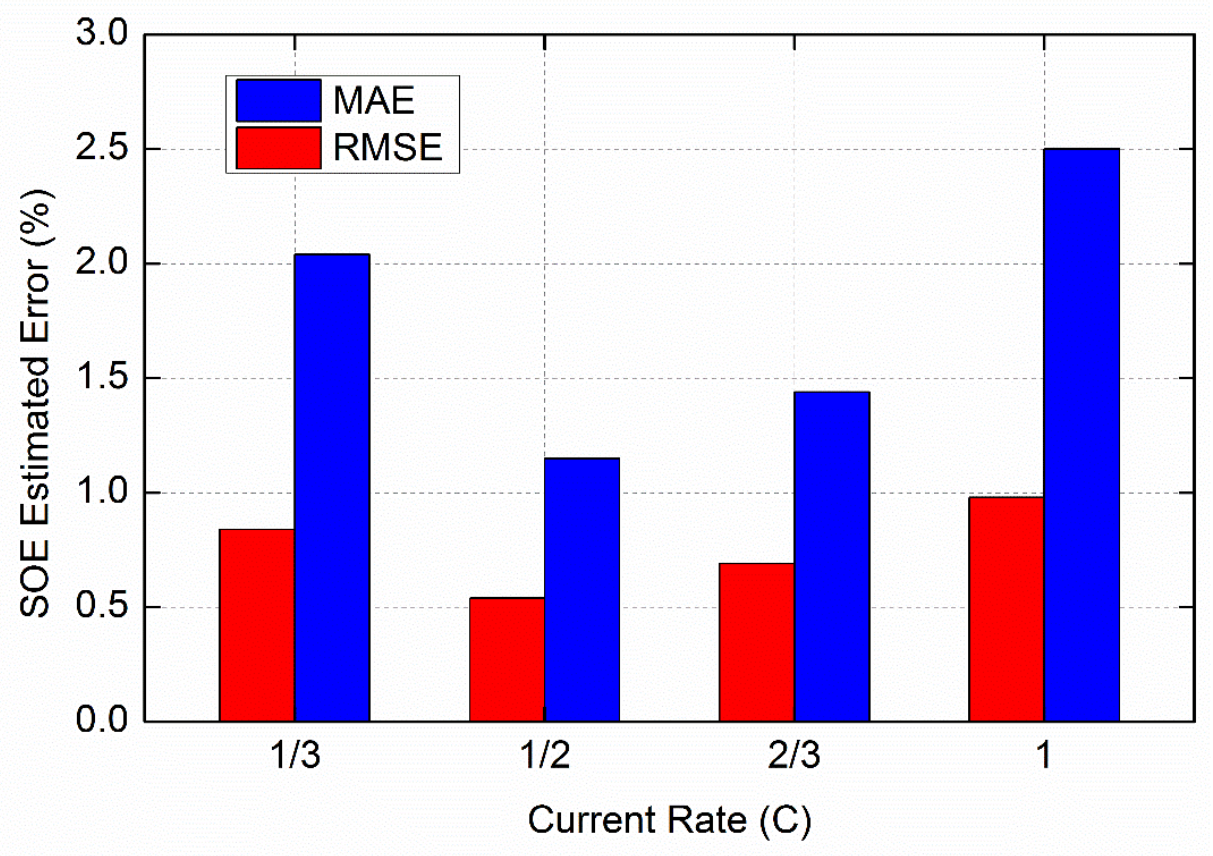

Fig. 11. SOE estimation errors with different discharge current rates.

In Fig. 11, the SOE estimation MAEs can be limited in a 2.5\% error band and the SOE

331 estimation RMSEs are less than $1.0 \%$ with different discharging current rates, 332 indicating that the proposed approach can perform well with different discharge current 333 rates.

\subsection{Maximum available energy estimation}

The battery maximum available energy is calculated by the proposed moving-window energy-integral and average methods. During the discharge process of a battery cell with $92 \mathrm{Ah}$ and $1 / 3 \mathrm{C}$ discharging current rate, the maximum available energy estimation results are plotted in Fig. 12. 


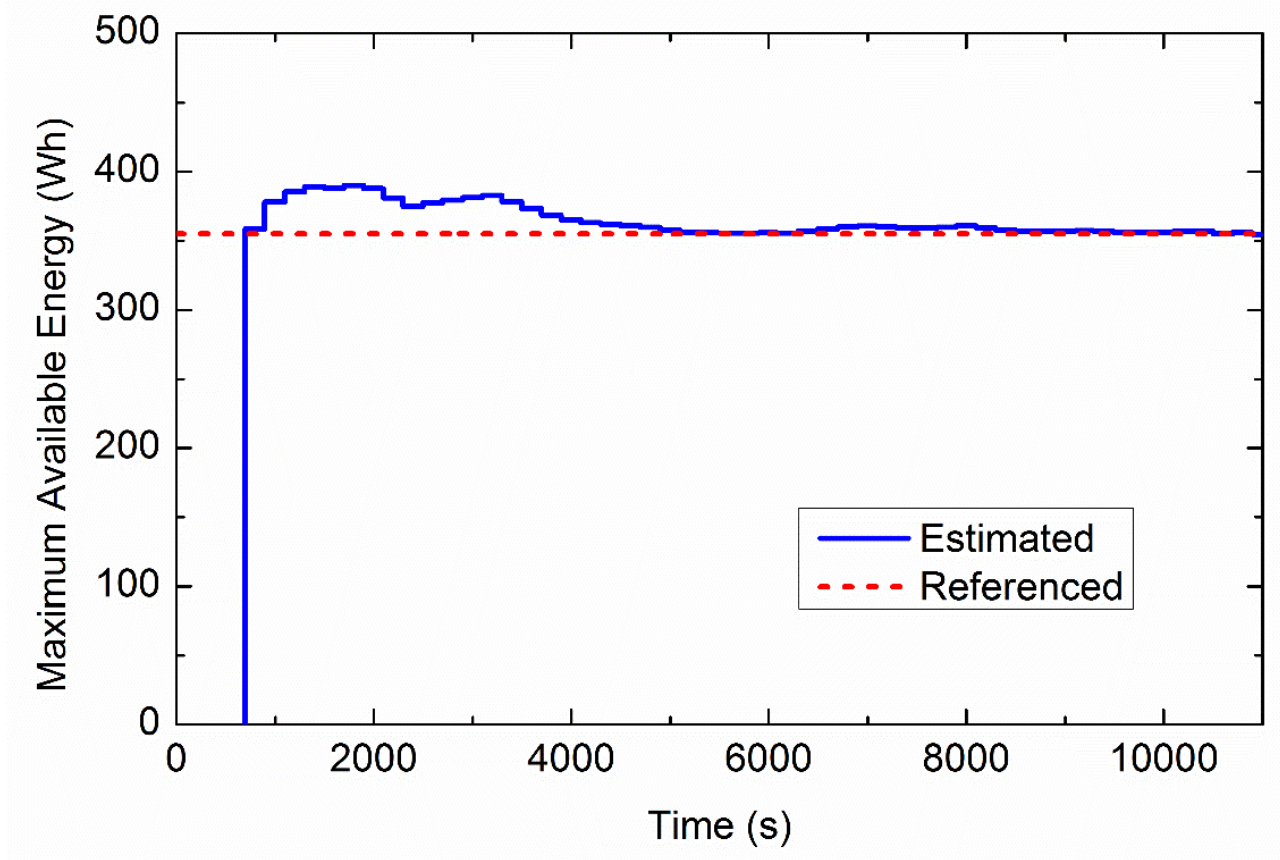

Fig. 12. Battery maximum available energy estimation results.

341 In Fig. 12, the proposed algorithm begins to estimate battery maximum available energy

342 at about $700 \mathrm{~s}$. This is because that the first $500 \mathrm{~s}$ are used for SOE estimation correction

343 and the followed $200 \mathrm{~s}$ are used for the first moving-window calculation. Although

344 some significant estimation errors occurred during the first $4000 \mathrm{~s}$, the estimated 345 maximum available energy can finally converge to the referenced value.

346 The battery test data at different aging levels are used to verify the effectiveness of the

347 proposed method for battery maximum available energy estimation. The estimated 348 results and relative estimation errors are shown in Fig. 13. 


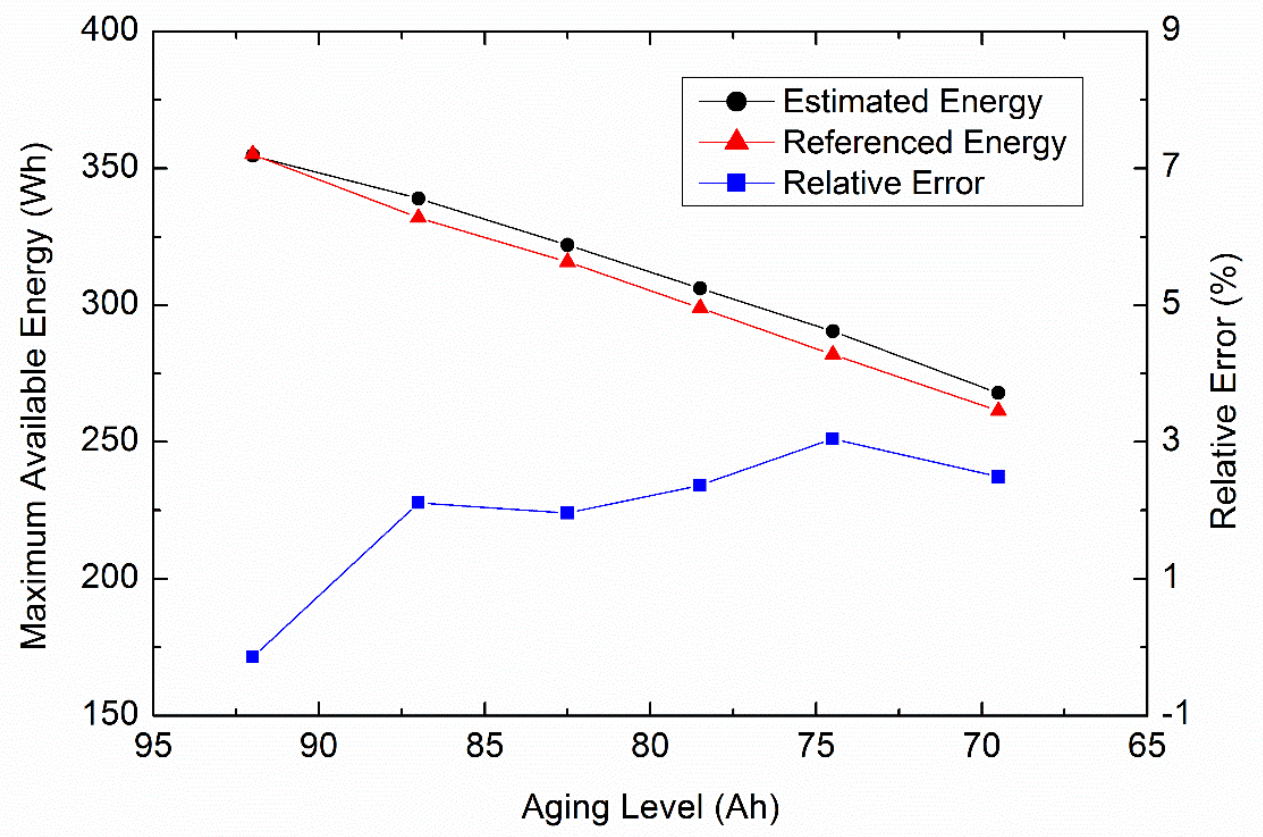

Fig. 13. Battery maximum available energy estimation results at different aging levels.

351 In Fig. 13, the estimated maximum available energies can track well with the referenced

352 values at different battery aging levels, and the relative estimation errors can be limited 353 in a $+/-3 \%$ error band, indicating that the proposed method is feasible for various battery 354 aging levels.

355 To verify the effectiveness of the proposed approach under different ambient 356 temperatures, the estimated processes were performed at $10{ }^{\circ} \mathrm{C}, 25{ }^{\circ} \mathrm{C}$ and $40{ }^{\circ} \mathrm{C}$, respectively, and the results are shown in Fig. 14. 


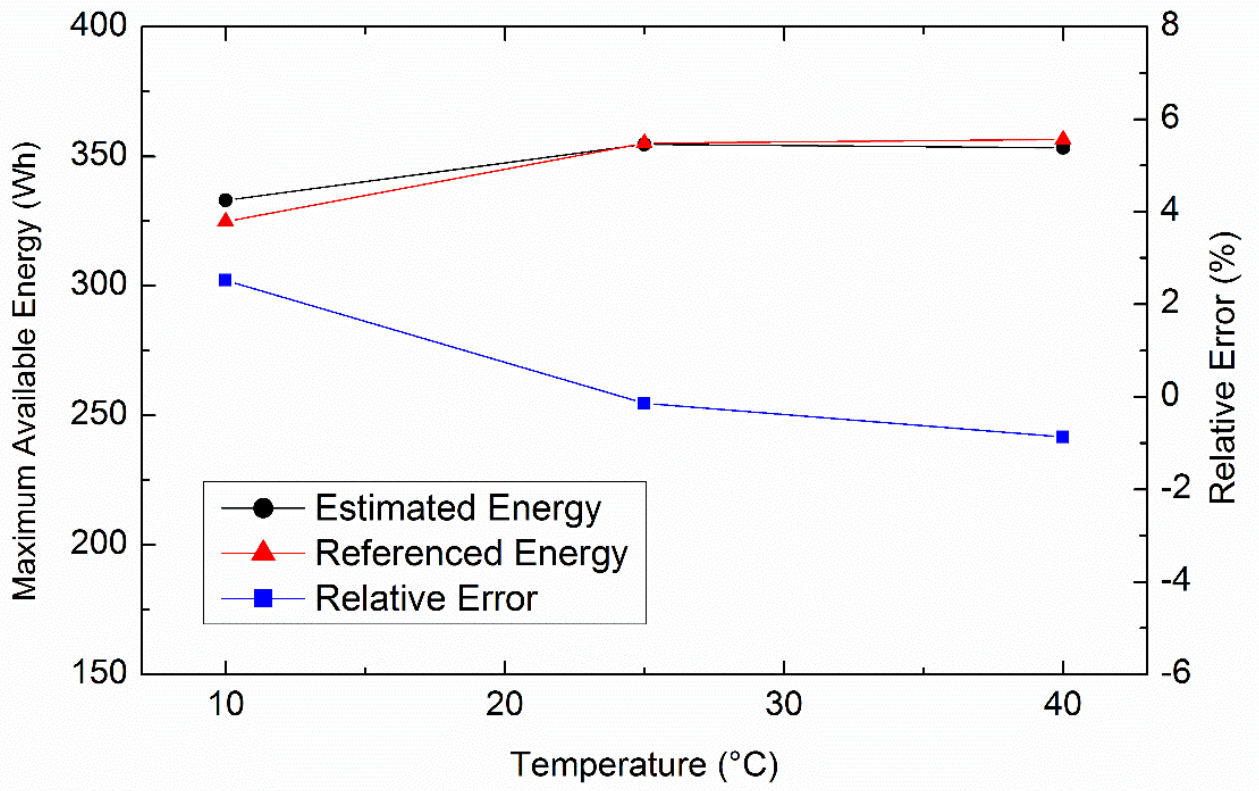

359 Fig. 14. Battery maximum available energy estimation results under different ambient temperatures.

Under various ambient temperatures, the estimated results presented in Fig. 14 show that the battery maximum available energy estimation method can work well at the above-mentioned temperatures and the relative estimation errors are able to be limited 364 in a $+/-2 \%$ error band.

365 To investigate the effectiveness of the proposed method with different charging current rates, the characteristic test data with four discharging current rates: 1/3C, 1/2C, 2/3C

367 and $1 \mathrm{C}$ at the room temperature $\left(25^{\circ} \mathrm{C}\right)$ were used to verify the battery maximum available estimation, and the results are shown in Fig. 15. 


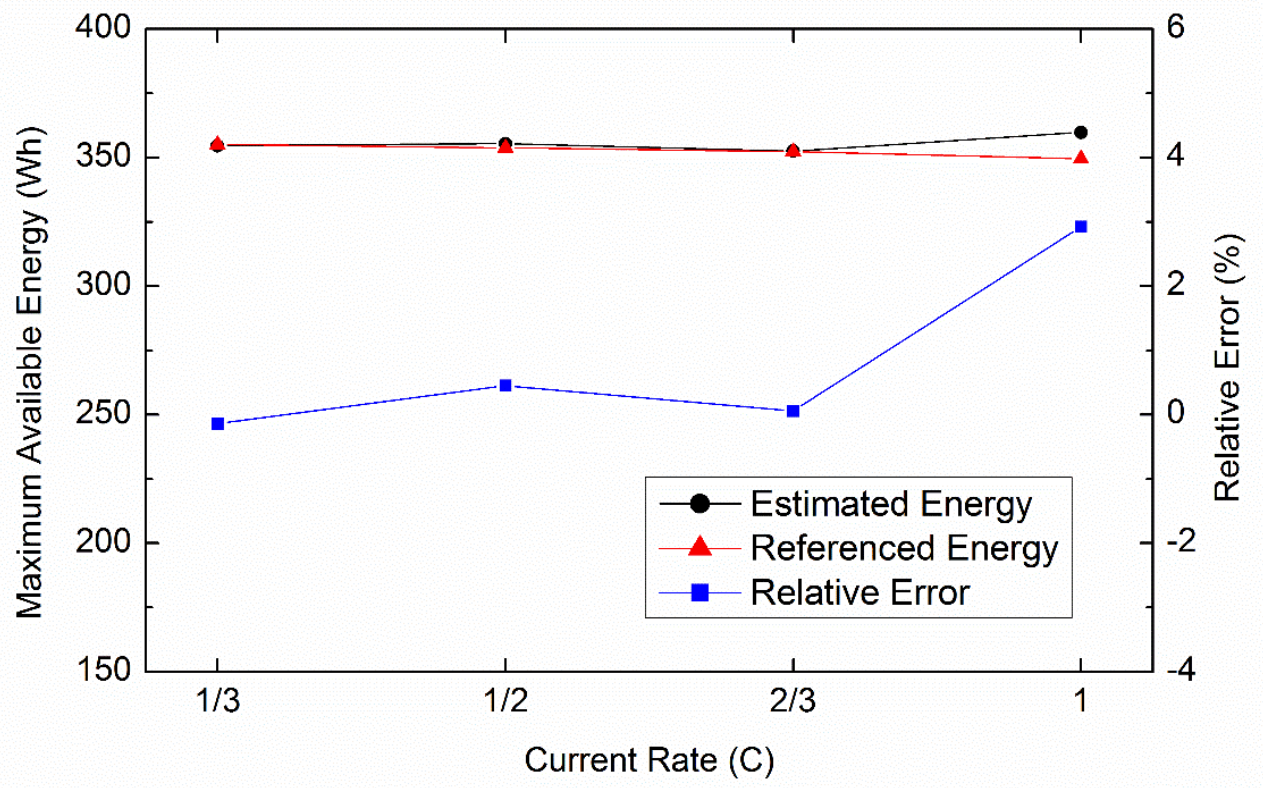

Fig. 15. Battery maximum available energy estimation results with different discharge current rates.

From Fig. 15, it can be seen that the estimated maximum available energies can follow the tracks of the referenced values well with different battery discharging current rates. The maximum estimated error is $2.92 \%$ at $1 \mathrm{C}$ current rate, showing that the proposed 375 method can handle different discharging current rates quite well.

\subsection{Dynamic stress test cycles verification}

377 The dynamic stress test (DST) cycle [31] is widely used to simulate the dynamic 378 changed loading conditions of batteries in real applications. The current profiles of DST cycles are depicted in Fig. 16(a). Before the DST test, the battery cell was fully charged in a constant current and constant voltage regime and the initial referenced SOE was $381100 \%$ while the initial SOE of the algorithm was set to an incorrect value, $48 \%$. The referenced SOE and the estimated SOE are compared in Fig. 16(b). It can be seen that 
383 the estimated SOE is able to track the referenced value quickly. Fig. 16(c) shows the 384 estimated SOE errors, in which the SOE estimation MAE and RMSE are $3.2 \%$ and $1.2 \%$, respectively. The battery maximum available energy estimation results are 386 plotted in Fig. 16(d). The resultant estimated maximum available energy is $324.2 \mathrm{Wh}$ 387 in contrast to the referenced value of $331.9 \mathrm{Wh}$, and the relative error is $2.32 \%$. The estimated results indicate that the proposed methods can perform well with small errors even under dynamic loading conditions.
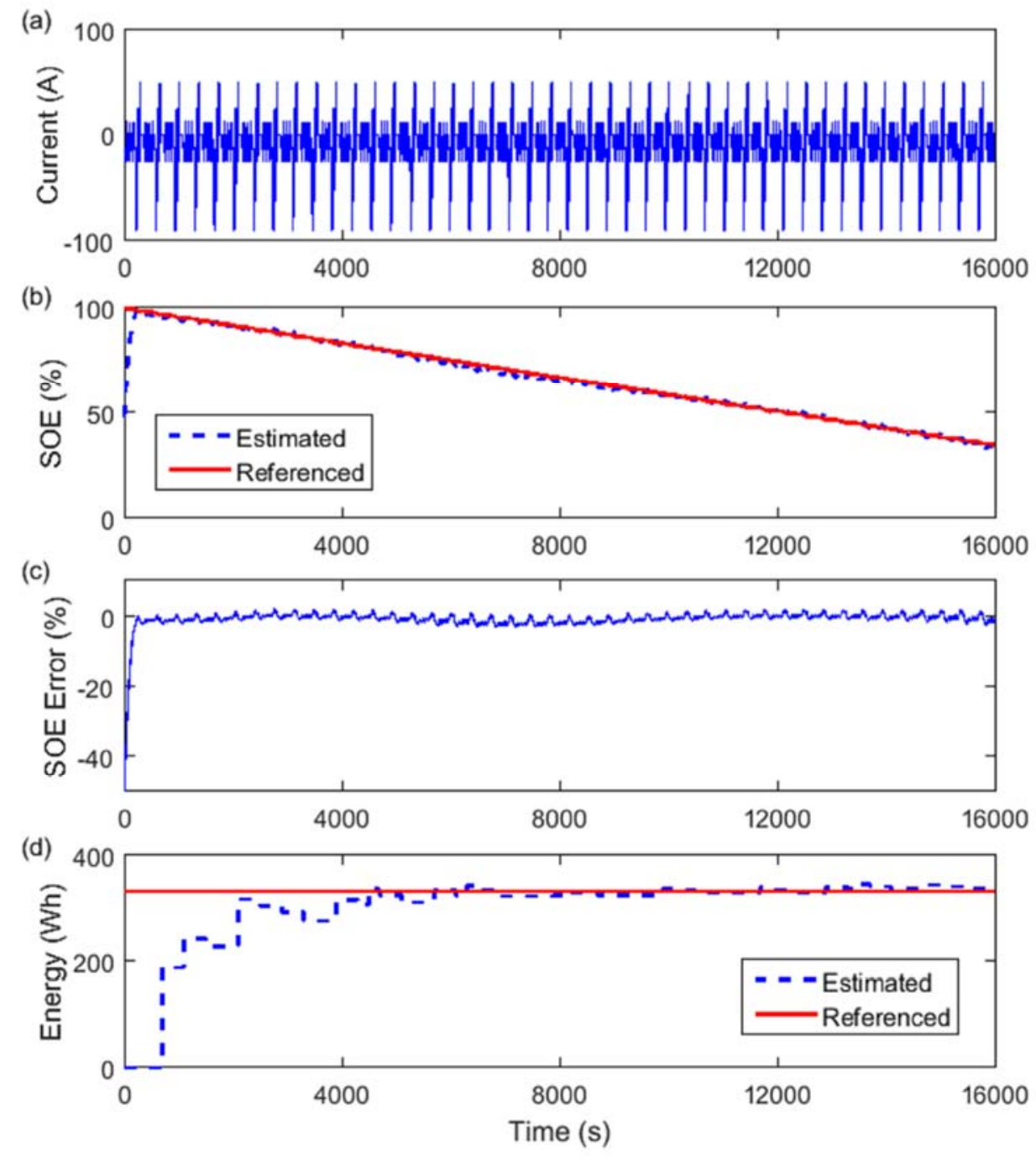

Fig. 16. Estimation results with DST cycles: (a) current profile of DST cycles, (b) 
392

393

394

395

396

397

398

399

400

401

402

403

404

405

406

407

408

409

410

411

412

SOE estimated results, (c) SOE estimated errors and (d) maximum available energy estimated results.

\section{Conclusion}

Different from SOC, SOE allows a direct determination of the ratio of battery remaining energy to maximum available energy, which is critical for energy optimization and management in energy storage systems. In order to estimate the battery SOE and maximum available energy accurately, the temperature, current rate and battery aging level dependencies of battery maximum available energy and SOE were systematically analyzed. The relationships between SOC and SOE for different influence factors, such as the ambient temperature, charging and discharging current rates, and battery aging levels, were explicitly quantified for the SOE estimation. Besides, a moving-window energy-integral and average method were incorporated for battery maximum available energy estimation. Experimental results show that the proposed approaches can estimate the battery maximum available energy and SOE with high precision even under the dynamic loading conditions. The robustness of the proposed estimation approaches against various operation conditions and cell aging levels is systematically evaluated. The simplicity of the proposed SOE estimation method can avoid heavy computation cost required by conventional model-based SOE estimation methods, which causes a severe computational burden to the microprocessor with limited computation capability used in BMSs, and therefore the proposed method has the potential to be implemented in practical applications. Further work will be conducted 
413

414

on the relationship between SOE and SOC and estimation of SOE and maximum available energy for other types of batteries.

\section{Acknowledgment}

This work was financially supported by the Automotive Australia 2020 Cooperative Research Centre (AutoCRC). The authors would also like to acknowledge the National Active Distribution Network Technology Research Center (NANTEC), Beijing Jiaotong University, for the prior work on battery tests.

\section{References}

[1] Su W, Eichi H, Zeng W, Chow M. A survey on the electrification of transportation in a smart grid environment. Industrial Informatics, IEEE Transactions on 2012;8:1-10.

[2] He H, Xiong R, Peng J. Real-time estimation of battery state-of-charge with unscented Kalman filter and RTOS $\mu$ COS-II platform. Appl Energy 2016;162:1410-8.

[3] Rahimi-Eichi H, Ojha U, Baronti F, Chow M. Battery management system: An overview of its application in the smart grid and electric vehicles. Industrial Electronics Magazine, IEEE 2013;7:4-16.

[4] Lu L, Han X, Li J, Hua J, Ouyang M. A review on the key issues for lithium-ion battery management in electric vehicles. J Power Sources 2013;226:272-88.

[5] Wang L, Pan C, Liu L, Cheng Y, Zhao X. On-board state of health estimation of LiFePO 4 battery pack through differential voltage analysis. Appl Energy 2016;168:465-72.

[6] Kim H, Shin KG. DESA: Dependable, efficient, scalable architecture for management of large-scale batteries. Industrial Informatics, IEEE Transactions on 2012;8:406-17.

[7] Wang S, Shang L, Li Z, Deng H, Li J. Online dynamic equalization adjustment of high-power lithium-ion battery packs based on the state of balance estimation. Appl Energy 2016;166:44-58. 
[8] Park H, Kim C, Park K, Moon G, Lee J. Design of a charge equalizer based on battery modularization. Vehicular Technology, IEEE Transactions on 2009;58:321623.

[9] Barillas JK, Li J, Günther C, Danzer MA. A comparative study and validation of state estimation algorithms for Li-ion batteries in battery management systems. Appl Energy 2015;155:455-62.

[10] Zhong L, Zhang C, He Y, Chen Z. A method for the estimation of the battery pack state of charge based on in-pack cells uniformity analysis. Appl Energy 2014;113:55864.

[11] Xu J, Mi CC, Cao B, Deng J, Chen Z, Li S. The state of charge estimation of lithium-ion batteries based on a proportional-integral observer. Vehicular Technology, IEEE Transactions on 2014;63:1614-21.

[12] Hu X, Sun F, Zou Y. Estimation of state of charge of a lithium-ion battery pack for electric vehicles using an adaptive Luenberger observer. Energies 2010;3:1586-603.

[13] Zheng L, Jiang J, Wang Z, Zhao T, He T. Embedded implementation of SOC estimation based on the Luenberger observer technique. 2014:1-4.

[14] Kim I. The novel state of charge estimation method for lithium battery using sliding mode observer. J Power Sources 2006;163:584-90.

[15] Kim I. A technique for estimating the state of health of lithium batteries through a dual-sliding-mode observer. Power Electronics, IEEE Transactions on 2010;25:101322 .

[16] Xiong R, Sun F, Chen Z, He H. A data-driven multi-scale extended Kalman filtering based parameter and state estimation approach of lithium-ion olymer battery in electric vehicles. Appl Energy 2014;113:463-76.

[17] Plett GL. Extended Kalman filtering for battery management systems of LiPBbased HEV battery packs: Part 1. Background. J Power Sources 2004;134:252-61.

[18] Plett GL. Extended Kalman filtering for battery management systems of LiPBbased HEV battery packs: Part 2. Modeling and identification. J Power Sources 2004;134:262-76.

[19] Plett GL. Extended Kalman filtering for battery management systems of LiPBbased HEV battery packs: Part 3. State and parameter estimation. J Power Sources 2004;134:277-92. 
[20] Mamadou K, Delaille A, Lemaire-Potteau E, Bultel Y. The state-of-energy: A new criterion for the energetic performances evaluation of electrochemical storage devices. ECS Transactions 2010;25:105-12.

[21] Mamadou K, Lemaire E, Delaille A, Riu D, Hing S, Bultel Y. Definition of a stateof-energy indicator ( $\mathrm{SoE}$ ) for electrochemical storage devices: application for energetic availability forecasting. J Electrochem Soc 2012;159:A1298-307.

[22] Liu X, Wu J, Zhang C, Chen Z. A method for state of energy estimation of lithiumion batteries at dynamic currents and temperatures. J Power Sources 2014;270:151-7.

[23] Dong G, Zhang X, Zhang C, Chen Z. A method for state of energy estimation of lithium-ion batteries based on neural network model. Energy 2015;90:879-88.

[24] Zhang W, Shi W, Ma Z. Adaptive unscented Kalman filter based state of energy and power capability estimation approach for lithium-ion battery. J Power Sources 2015;289:50-62.

[25] Liu HW, Wang HF, Guo C. State of energy estimation based on AUKF for lithium battery used on pure electric vehicle. 2013;608:1627-30.

[26] Wang Y, Zhang C, Chen Z. A method for joint estimation of state-of-charge and available energy of LiFePO 4 batteries. Appl Energy 2014;135:81-7.

[27] He H, Zhang Y, Xiong R, Wang C. A novel Gaussian model based battery state estimation approach: State-of-Energy. Appl Energy 2015;151:41-8.

[28] Moré JJ. The Levenberg-Marquardt algorithm: implementation and theory. In: Anonymous Numerical analysis: Springer; 1978, p. 105-116.

[29] Khan MR, Mulder G, Van Mierlo J. An online framework for state of charge determination of battery systems using combined system identification approach. J Power Sources 2014;246:629-41.

[30] Han X, Ouyang M, Lu L, Li J. Simplification of physics-based electrochemical model for lithium ion battery on electric vehicle. Part II: Pseudo-two-dimensional model simplification and state of charge estimation. J Power Sources 2015;278:814-25.

[31] United States Advanced Battery Consortium. Electric vehicle battery test procedures manual. USABC, Jan 1996. 